\title{
Pearls \& Oy-sters: Paraneoplastic cerebral vasculitis
}

\section{Rare cause of spontaneous convexity subarachnoid hemorrhage}

Anuja Patil, MD, DM, Ritu Shree, MD, Darakhshan Naheed, MD, Manoj K. Goyal, MD, DM, Sahil Mehta, MD, DM, Chirag K. Ahuja, MD, DM, Bishan D. Radotra, MD, DM, and Vivek Lal, MD, DM

Neurology ${ }^{\circledR}$ 2018;90:e815-e817. doi:10.1212/WNL.0000000000005025

\section{Pearls}

- Convexity subarachnoid hemorrhage (SAH) represents $6 \%$ to $7 \%$ of all cases of subarachnoid hemorrhage, with cerebral amyloid angiopathy and reversible cerebral vasospasm accounting for $55 \%$ to $70 \%$ of all cases.

\section{Oy-sters}

- Convexity SAH due to cerebral vasculitis of paraneoplastic origin is a rare entity, the exact incidence of which remains undetermined.

\section{Case report}

A 47-year-old woman was apparently of normal health until 10 days before presentation to our emergency services when she developed sudden-onset, severe holocranial headache and vomiting followed 6 days later by altered sensorium. There was no history of fever or any other systemic complaints. She was admitted and evaluated at another center and was later referred to our hospital. On examination, she had lymphadenopathy in the left cervical, supraclavicular, and left axillary regions. There was a $4 \times 3 \mathrm{~cm}$, hard, nontender, ulcerating mass in her left breast. She was in altered sensorium (Glasgow Coma Scale score E3M4V2) with neck rigidity and positive Kernig sign. She had palsy of the left seventh nerve, right third nerve, and bilateral sixth nerves. Deep tendon reflexes were brisk, and plantar responses were bilaterally extensor. Based on history and examination findings, the possibility of carcinomatous meningitis with hemorrhagic leptomeningeal metastases was considered and she was evaluated. Routine hemogram, biochemical investigations, and coagulogram were normal. She had a noncontrast CT scan of the brain done elsewhere, which revealed the presence of bilateral high parietal sulcal SAH (figure, A). CT angiography did not reveal any evidence of aneurysm or arteriovenous malformation. MRI scan of the brain showed SAH in bilateral parieto-occipital regions (figure, B and $\mathrm{C}$ ), and magnetic resonance venography was normal. In view of the clinical picture and the above investigational profile, an alternative possibility of paraneoplastic reversible cerebral vasospasm with convexity SAH was also considered, and she underwent diagnostic digital subtraction angiography. This revealed extensive and multifocal narrowing of small-sized vessels suggestive of either a vasospasm or cerebral vasculitis (figure, D). Meanwhile, a CSF examination revealed the presence of malignant cells on cytocentrifugation, confirming the diagnosis of neoplastic meningitis. She was started on IV methylprednisolone for symptomatic relief. Further radiotherapy and chemotherapy including intrathecal methotrexate were planned. However, she progressively deteriorated to Glasgow Coma Scale score 7/15 by day 2 of admission for which she was intubated and given ventilator support. A Tru-Cut biopsy of the breast lesion was performed, which was suggestive of a grade III ductal infiltrating carcinoma. Repeat brain MRI showed resolving SAH and extensive bilateral diffusion restriction suggestive of infarcts in the brain with spinal metastases. She succumbed on day 4 of admission. She underwent an autopsy, which revealed a dense patch of SAH along the inferior surface of the left cerebellar hemisphere. Major vessels of the circle of Willis did not show any aneurysmal dilation, atheroma, or thrombosis. Histologic examination revealed carcinomatous meningitis.
Correspondence

Dr. Lal

vivek|44@yahoo.com

From the Departments of Neurology (A.P., R.S., D.N., M.K.G., S.M., V.L.), Radiodiagnosis (C.K.A.), and Histopathology (B.D.R.), Postgraduate Institute of Medical Education and Research, Chandigarh, India.

Go to Neurology.org/N for full disclosures. Funding information and disclosures deemed relevant by the authors, if any, are provided at the end of the article. 

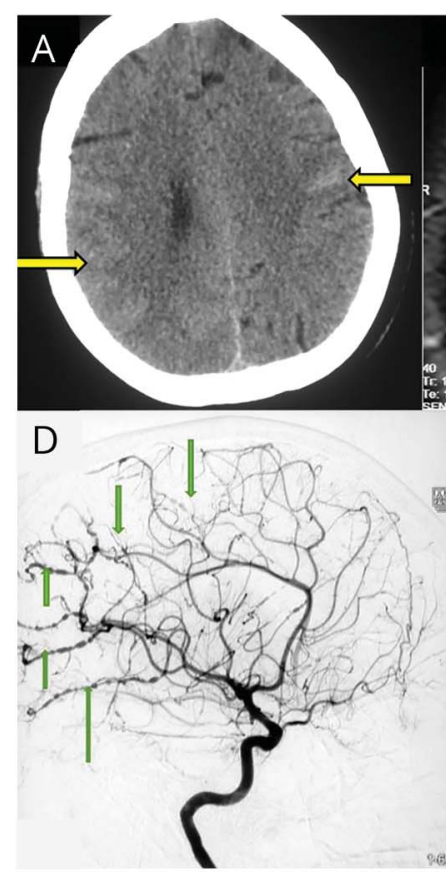
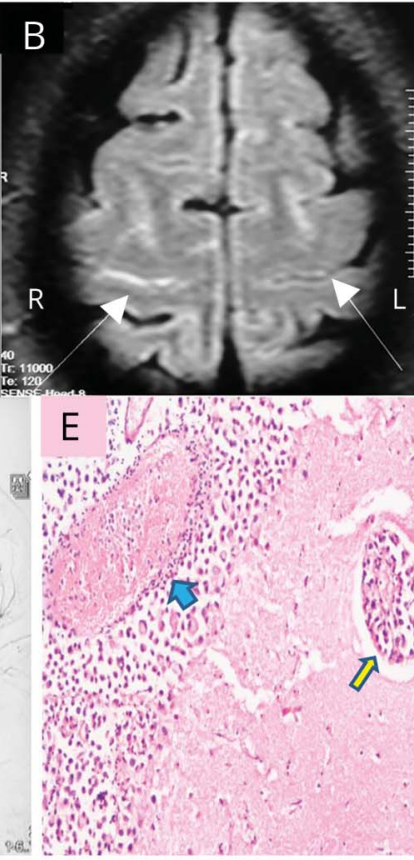
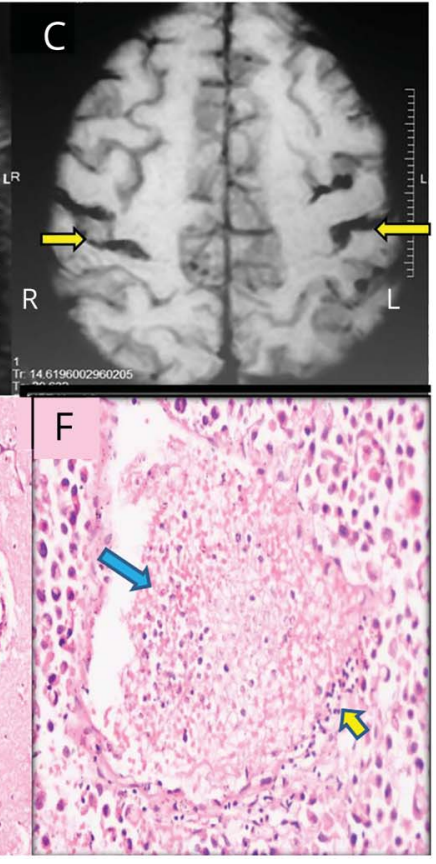

(A) Noncontrast CT of the head showing bilateral parieto-occipital sulcal hemorrhage (yellow arrows). (B and C) Magnetic resonance fluid attenuated inversion recovery images ( $B$, white arrows) and susceptibility-weighted images $(C$, yellow arrows) showing bilateral parieto-occipital sulcal hemorrhage. (D) Digital subtraction angiography showing beading of vessels suggestive of vascular spasm (green arrows). (E) Subarachnoid space and Virchow-Robin space (yellow arrow) are distended with tumor cells. The smaller blood vessel shows vasculitis (blue arrow) (H\&E stain, original magnification $\times 20$ ). (F) A leptomeningeal blood vessel shows vasculitis (yellow arrow) with fibrin thrombus formation (blue arrow) and is surrounded by tumor cells (H\&E stain, original magnification $\times 40)$. $H \& E=$ hematoxylin \& eosin.
The Virchow-Robin spaces were distended and filled with tumor cells (figure, E) positive for cytokeratin but negative for the estrogen receptor, progesterone receptor, and HER2 (human epidermal growth factor receptor 2). There was extensive tumor infiltration of the spinal meninges and nerve roots. The smaller branches of the blood vessels of circle of Willis showed periarterial infiltration and intimal inflammation and fibrin deposition without any necrosis or granuloma formation (figure, F), features consistent with paraneoplastic vasculitis. The larger cerebral blood vessels were encased by tumor cells but were devoid of infiltration. In addition, there was extensive metastasis of breast carcinoma to axillary, pectoral, mesenteric, and portal hepatic lymph nodes, spinal vertebrae, adrenals, small intestine, urinary bladder, and cervix. A final diagnosis of metastatic breast carcinoma with carcinomatous meningitis with paraneoplastic cerebral vasculitis and convexity SAH was made.

\section{Discussion}

Nontraumatic convexity $\mathrm{SAH}$ is a rare clinical entity with causes varying from relatively benign, such as cerebral amyloid angiopathy, to malignant, such as paraneoplastic cerebral angiitis (table e-1, http://links.lww.com/WNL/A193). The most common causes of convexity $\mathrm{SAH}$ include cerebral amyloid angiopathy in patients 60 years and older and reversible vasospasm in patients younger than 60 years, together accounting for about $55 \%$ to $70 \%$ of cases in different series. Other rare causes include CNS vasculitis, drugs (ephedrine, amphetamine, etc.), posterior reversible encephalopathy syndrome, cerebral venous sinus thrombosis, vascular stenosis, cavernomas, and bleeding disorders. ${ }^{1,2}$ The most common clinical features include transient focal neurologic deficits, epileptic seizures, and headaches. The classic thunderclap headache is relatively uncommon in convexity SAH and, if present, suggests the etiology to be either reversible cerebral vasospasm or cerebral venous sinus thrombosis. As the etiology of convexity SAH differs from classic aneurysmal $\mathrm{SAH}$, the diagnostic workup for convexity $\mathrm{SAH}$ differs from that of aneurysmal SAH and is directed toward identification of the exact underlying etiology.

The clinical workup includes a thorough general physical and systemic examination in addition to a routine neurologic examination. Routine evaluation should be directed by clinical signs and include a detailed hemogram, biochemistry, coagulation profile, vasculitic workup, cardiology evaluation (including ECG and echocardiogram), screening for HIV, hepatitis $B$ virus, and hepatitis $\mathrm{C}$ virus, as well as chest $\mathrm{CT}$ and abdomen/whole-body PET to detect systemic malignancy. The neuroimaging workup includes MRI of the brain with diffusion- and susceptibility-weighted imaging, magnetic resonance venography, and magnetic resonance angiography. Alternatively, a contrast-enhanced CT scan of the brain with $\mathrm{CT}$ angiography and venography may be performed. If the cause remains undetermined, digital subtraction angiography may be used. The treatment of convexity SAH is directed toward amelioration of the underlying etiology. ${ }^{1-3}$

Of patients who succumb to systemic cancers, $7.1 \%$ have evidence of cerebral hemorrhage on autopsy. Types of 
hemorrhage include parenchymal hemorrhage (intratumoral bleeds [24.5\%], bleeding secondary to tumor-induced coagulopathy [36\%], and hypertensive intracerebral hemorrhage $[3.6 \%])$, primary subdural hematoma $(25.8 \%)$, and primary subarachnoid hemorrhage (9.8\%). The principal causes of bleeds include coagulopathies (disseminated intravascular coagulation, microangiopathic hemolytic anemia, thrombocytopenia, and liver disease), bleeding into a tumor (parenchymal, subdural, epidural, or subarachnoid), rupture of a neoplastic aneurysm, chemotherapy-induced hematologic complications, and infections with vasculitis or mycotic aneurysm formation. ${ }^{4,5}$ Involvement of cerebral blood vessels in patients with systemic malignancy can be attributable to either (1) direct vessel infiltration or compression by metastatic tumor cells, especially with tumor growth in the VirchowRobin spaces, or (2) a paraneoplastic phenomenon. ${ }^{5,6}$ In our patient, histopathologic examination revealed cerebral vasculitis without any infiltration of tumor cells into the vessel wall. This suggests that cerebral vasculitis in the index patient was paraneoplastic.

Paraneoplastic angiitis of the CNS is a rare occurrence. There are case reports of paraneoplastic CNS vasculitis associated with breast cancer ${ }^{5}$ and Hodgkin lymphoma. ${ }^{6}$ Giant cell arteritis running a concordant course with associated malignancy has been reported with other solid organ malignancies. ${ }^{7}$ Several pathogenic mechanisms have been invoked to explain the occurrence of paraneoplastic cerebral vasculitis. These include (1) tumor cells inducing an immunologic reaction against vascular endothelium because of molecular mimicry, (2) endothelial injury due to release of various proinflammatory cytokines by tumor cells, (3) deposition of tumor proteins on the vessel wall followed by induction of delayed hypersensitivity reaction, and (4) deposition of circulating immune complexes containing tumor antigens on the vessel wall. ${ }^{7}$ Concomitant precipitating events (such as various infections or use of chemotherapeutic drugs) may also act as an initial trigger for an immune complex-mediated disorder. Whatever the mechanism, paraneoplastic cerebral vasculitis is associated with poor prognosis and needs to be treated aggressively with corticosteroids and other immunosuppressants.

Spontaneous convexity SAH as the presenting manifestation of paraneoplastic cerebral vasculitis has not yet been described. Our case stresses the need to keep this rare possibility in mind when evaluating patients with convexity SAH and to provide appropriate evaluation of these patients.

\section{Author contributions}

Anuja Patil: drafting the article, analysis, interpretation of the data, manuscript preparation. Ritu Shree: drafting the article, interpretation of the data, manuscript preparation. Darakshan Naheed: drafting the article and revising its intellectual content. Manoj K. Goyal: drafting the article or revising its intellectual content, analysis or interpretation of the data. Sahil Mehta: drafting the article and revising its intellectual content. Chirag K. Ahuja: drafting the article and revising its intellectual content. Bishan D. Radotra: drafting the article and revising its intellectual content. Vivek Lal: drafting the article and revising its intellectual content.

\section{Study funding}

No targeted funding reported.

\section{Disclosure}

The authors report no disclosures relevant to the manuscript. Go to Neurology.org/N for full disclosures.

\section{References}

1. Khurram A, Kleinig T, Leyden J. Clinical associations and causes of convexity subarachnoid haemorrhage. Stroke 2014;45:1151-1153.

2. Renou P, Tourdias T, Fleury O, et al. Atraumatic nonaneurysmal sulcal subarachnoid hemorrhage: a diagnostic work up based on case series. Cerebrovasc Dis 2012;34: $147-152$.

3. Cuvinciuc V, Viguier A, Calviere L, et al. Isolated acute nontraumatic cortical subarachnoid hemorrhage. Am J Neuroradiol 2010;31:1355-1362.

4. Graus F, Rogers LR, Posner JB. Cerebrovascular complications in patients with cancer. Medicine 1985;64:16-35.

5. Taccone FS, Salmon I, Marechal R, et al. Paraneoplastic vasculitis of central nervous system presenting as recurrent cryptogenic stroke. Int J Clin Oncol 2007;12:155-159.

6. Rosen CL, DePalma L, Morita A. Primary angiitis of the central nervous system as a first presentation in Hodgkin's disease: a case report and review of the literature. Neurosurgery 2000;46:1504-1510.

7. Buggiani G, Krysenka A, Grazzini M, et al. Paraneoplastic vasculitis and paraneoplastic vascular syndromes. Dermatol Ther 2010;23:597-605. 


\section{Neurology}

\section{Pearls \& Oy-sters: Paraneoplastic cerebral vasculitis: Rare cause of spontaneous convexity subarachnoid hemorrhage}

Anuja Patil, Ritu Shree, Darakhshan Naheed, et al.

Neurology 2018;90;e815-e817

DOI 10.1212/WNL.0000000000005025

This information is current as of February 26, 2018

Updated Information \& Services

References

Subspecialty Collections

Permissions \& Licensing

Reprints including high resolution figures, can be found at: http://n.neurology.org/content/90/9/e815.full

This article cites 7 articles, 2 of which you can access for free at: http://n.neurology.org/content/90/9/e815.full\#ref-list-1

This article, along with others on similar topics, appears in the following collection(s):

All Cerebrovascular disease/Stroke

http://n.neurology.org/cgi/collection/all_cerebrovascular_disease_strok

All Headache

http://n.neurology.org/cgi/collection/all_headache

Arteriovenous malformation

http://n.neurology.org/cgi/collection/arteriovenous_malformation Metastatic tumor

http://n.neurology.org/cgi/collection/metastatic_tumor

Subarachnoid hemorrhage

http://n.neurology.org/cgi/collection/subarachnoid_hemorrhage

Information about reproducing this article in parts (figures,tables) or in its entirety can be found online at:

http://www.neurology.org/about/about_the_journal\#permissions

Information about ordering reprints can be found online:

http://n.neurology.org/subscribers/advertise

Neurology ${ }^{\circledR}$ is the official journal of the American Academy of Neurology. Published continuously since 1951 , it is now a weekly with 48 issues per year. Copyright @ 2018 American Academy of Neurology. All rights reserved. Print ISSN: 0028-3878. Online ISSN: 1526-632X.

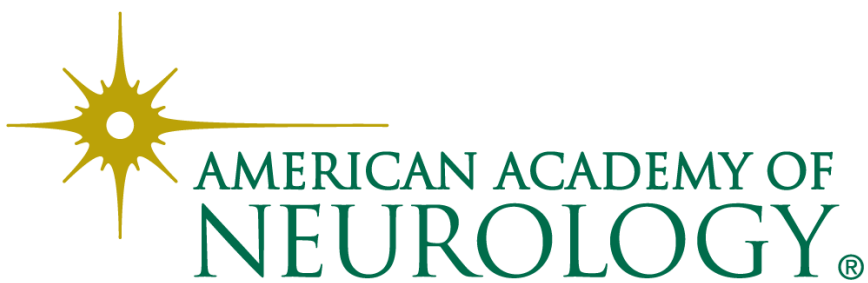

